\title{
A Low-Cost System for Measuring ppb-Level $\mathrm{NO}_{2}{ }^{*}$
}

\author{
by \\ In Hyeog Oh \\ KT\&G Central Research Institute, 302 Shinseong-dong, Yuseong-gu, Daejeon 305-805, South Korea
}

\section{SUMMARY}

A low-cost system to measure low-level nitrogen dioxide $\left(\mathrm{NO}_{2}\right)$ in an atmosphere was developed. Its major component included a sensor comprising filter paper treated with 3,3'-dimethylbenzidine (o-tolidine), a compound that reacts with $\mathrm{NO}_{2}$ to generate color proportional to the $\mathrm{NO}_{2}$ contacted. In addition to the system development, its utility was optimized and the characteristics of the sensor were defined. Originally developed to determine the $\mathrm{NO}_{2}$ levels during direct-fired tobacco curing, the system may be used to determine the $\mathrm{NO}_{2}$ levels in other situations. [Beitr. Tabakforsch. Int. 21 (2005) 390-401]

\section{ZUSAMMENFASSUNG}

Ein kostengünstiges System zur Messung geringer Mengen von Stickstoffdioxid $\left(\mathrm{NO}_{2}\right)$ in der Luft wurde entwickelt. Die Hauptkomponente des Systems bestand aus einem Sensor, der mit 3,3'-Dimethylbenzidin (o-Tolidin) behandeltes Filterpapier enthielt. Dies ist eine Verbindung, die mit $\mathrm{NO}_{2}$ in Abhängigkeit von der aufgetretenen $\mathrm{NO}_{2}$-Konzentration unter Farbentwicklung reagiert. Zusätzlich zur Systementwicklung wurde die Anwendung optimiert und die Eigenschaften des Sensors wurden beschrieben. Das System wurde entwickelt, um $\mathrm{NO}_{2}$-Konzentrationen während der Tabaktrocknung unter Direktfeuerung zu bestimmen, es kann jedoch auch zur Bestimmung von $\mathrm{NO}_{2}$-Konzentrationen in anderen Situationen dienen. [Beitr. Tabakforsch. Int. 21 (2005) 390-401]

\section{RESUME}

Un système peu coûteux a été développé pour mesurer les faibles taux de dioxydes de nitrite $\left(\mathrm{NO}_{2}\right)$ dans une atmosphère. L'élément principal du système comporte un détecteur équipé de papier filtre traité au 3,3'-diméthylbenzidine (o-tolidine), composé qui réagit avec du $\mathrm{NO}_{2}$ en générant une coloration en fonction du taux de $\mathrm{NO}_{2}$ présent. En plus du développement du système, son utilisation a été optimisée et les caractéristiques du détecteur ont été décrites. Ce système a été d'abord conçu pour déterminer les teneurs en $\mathrm{NO}_{2}$ dans les tabacs séchés au feu, mais ce système peut également être utilisé pour déterminer les taux de $\mathrm{NO}_{2}$ dans d'autres situations. [Beitr. Tabakforsch. Int. 21 (2005) 390-401]

\section{INTRODUCTION}

Several aromatic amines may be used to detect nitrogen dioxide $\left(\mathrm{NO}_{2}\right)$ by color reactions. By detecting the color change induced by $\mathrm{NO}_{2}$ on filter paper impregnated with such a compound, 3,3'-dimethylbenzidine (o-tolidine), it was found that $\mathrm{NO}_{2}$ could be detected. The calibration curve between $\mathrm{NO}_{2}$ levels and absorbance changes at peak wavelength showed good linear relationships, indicating the possibility of measuring ppb-level $\mathrm{NO}_{2}$. Finally, a comparison between the method described herein and a reference method indicated that $\mathrm{NO}_{2}$ at ppb-levels could successfully be measured. In addition, a low-cost opto-electronic system for efficiently measuring ppb-level $\mathrm{NO}_{2}$ in environmental air or exhaust gases by colorimetry was designed.

\section{DEVELOPMENT OF THE SYSTEM}

Nitrogen oxide $\left(\mathrm{NO}_{\mathrm{x}}\right)$, the term used to describe the sum of nitric oxide (NO), nitrogen dioxide $\left(\mathrm{NO}_{2}\right)$ and other oxides of nitrogen, is formed by combustion of fuels and is one of the main components of environmental pollutants involved in acid rain and photochemical smog. Because $\mathrm{NO}_{\mathrm{x}}$ significantly impacts human health, much current research is devoted to quantitatively determining the atmospheric $\mathrm{NO}_{\mathrm{x}}$ level and reducing it. A prerequisite for $\mathrm{NO}_{\mathrm{x}}$ level reduc- 
tion is the ability to determine accurately its levels in ambient air, levels which typically are in the low-ppb range. Instruments for $\mathrm{NO}_{\mathrm{x}}$ detection have been developed utilizing chemical luminescence (1) and an optical gas sensor (2). Even though these are considered sensitive and accurate, they are too expensive, fragile and complicated to be used as instruments on-site tests. Other devices include badges, tapes, and tubes to capture the $\mathrm{NO}_{\mathrm{x}}$ for subsequent colorimetric analysis $(3,4)$. Their disadvantage is that they cannot be utilized to monitor real-time $\mathrm{NO}_{\mathrm{x}}$ concentrations in the field. Some convenient, inexpensive personal indicator devices have been developed for detecting $\mathrm{NO}_{\mathrm{x}}$. However, their accuracy and detection are limited $(5,6)$.

When fuel burns at high temperatures, $\mathrm{NO}_{\mathrm{x}}$ is formed. Its two major sources are transportation (motor vehicles) and stationary fuel combustion (electric utilities, industrial boilers). The most significant component in $\mathrm{NO}_{\mathrm{x}}$ is $\mathrm{NO}_{2}$. $\mathrm{NO}_{2}$ is a brownish, highly reactive gas, present in urban atmospheres. It is formed by oxidation of $\mathrm{NO}$ in the $\mathrm{NO}_{\mathrm{x}}$ emissions. $\mathrm{NO}_{2}$ is reported to be highly toxic to humans, irritating the lungs, inducing bronchitis and pneumonia, and lowering resistance to respiratory infection. $\mathrm{NO}_{2}$ is important in both ozone and acid rain generation, both of which are detrimental to terrestrial and aquatic ecosystems. In addition to its reduction, the detection of $\mathrm{NO}_{2}$ is important. Various instruments for the detection of $\mathrm{NO}_{2}$ have been developed. They involve chemical luminescence, optical gas sensors, and colorimetric methods $(1,2)$. While these instruments are sensitive and accurate for detecting $\mathrm{NO}_{2}$, they have disadvantages with regard to cost, convenience and size. Compact and low-cost systems to detect $\mathrm{NO}_{2}$ have recently been developed. They include an amperometric $\mathrm{NO}_{2}$ sensor (7), an opto-electronic unit with optical fibers (8), and another type of opto-electronic system with porous glass $(9,10)$. Thus, many studies $(1,2,7-10)$ have been conducted to develop systems for $\mathrm{NO}_{2}$ detection to ultimately reduce the $\mathrm{NO}_{2}$ level in environmental air or exhaust gas.

In the study described herein, a low-cost opto-electronic system and method for measuring ppb-level $\mathrm{NO}_{2}$ with filter paper impregnated with a colorimetric reagent was developed. Colorimetric reagents sensitive to $\mathrm{NO}_{2}$ include 2,5bis(4-aminophenyl)-1,3,4-oxadiazole (APOX), sulfanilamide (SFA), $N, N$-dimethyl-1-naphthylamine (DMNA), and 3,3'-dimethylbenzidine (o-tolidine). It has been reported that $N, N$ '-diphenylbenzidine also provides a color reaction with $\mathrm{NO}_{2}(11)$.

$o$-Tolidine was selected as the colorimetric reagent in the present study. It was applied to the newly developed device designed to efficiently increase the sensitivity of the color sensor through forced constant-flow and then diffusion of $\mathrm{NO}_{2}$. It is a simple, low-cost system for in-situ colorimetric measurement of ppb-levels $\mathrm{NO}_{2}$ in environmental air or exhaust gas. The constant forced flow of low levels of $\mathrm{NO}_{2}$ through the device induces a reaction with the $o$-tolidine deposited on a filter paper substrate. As the gas diffuses through the treated substrate, the reagent color changes in proportion to the $\mathrm{NO}_{2}$ level. By measurement of the color change with an opto-electronic system, the $\mathrm{NO}_{2}$ concentration is determined quantitatively.

In the study of this newly developed instrument for $\mathrm{NO}_{2}$ detection, an attempt was made to optimize some adjust- able factors affecting the reproducibility and life-time of the chemical sensor, its capacity on upper detection limit, continuous measurement, and the sensitivity of the device, which should be identified prior to application to the field test.

Initially, the instrument was developed to monitor $\mathrm{NO}_{x}$, particularly its $\mathrm{NO}_{2}$ content, in indirect-fired tobacco-curing barns. Green tobacco contains little tobacco-specific nitrosamines (TSNAs). Research conducted during 1998 and 1999 showed that $\mathrm{NO}_{2}$ generated in modern direct-fired curing barns fueled with propane contributes to TSNA formation during flue-curing of tobacco $(12,13)$. TSNAs are classified as potent animal tumorigens even though none has induced respiratory tract tumors when administered via inhalation. To reduce or eliminate TSNA formation in tobacco during flue-curing, substantial reduction of the $\mathrm{NO}_{2}$ level is considered necessary despite the fact that the mainstream smoke condensates from cigarettes made from flue-cured tobacco with normal and reduced levels of TSNAs show no significant difference in their biological effect (Neutral Red cytotoxicity, Ames test mutagenicity with several Salmonella typhimurium strains) (14). Periodic monitoring of $\mathrm{NO}_{2}$ levels during curing is considered essential in the maintenance of curing equipment. Therefore, it needed to be supported by development of an $\mathrm{NO}_{2}$ detecting system which offers a low-cost, compact, convenient and accurate method of measurement. Since the system herein described is successful in measuring ppb-level $\mathrm{NO}_{\mathrm{x}}$ in tobacco-curing barns, it may be extended to other industrial sites.

\section{Materials and methods}

Commercial-grade $o$-tolidine was employed without further purification. Whatman filter paper (No. 4) was used as the sensor base for detecting $\mathrm{NO}_{2}$. A $5 \mathrm{~g} / \mathrm{L}$ solution of $o$ tolidine in ethanol was used to impregnate the filter paper by a 5 -min immersion in the solution. The $o$-tolidine solution-impregnated filter paper was evaporated to dryness under reduced pressure at room temperature for $1.0 \mathrm{~h}$. Then, the filter paper was stored in desiccators in the dark. Commercial-grade $\mathrm{NO}_{\mathrm{x}}$ (National Specialty Gases, Raleigh, NC) was used as the standard (Table 1).

To determine the optimal peak wavelength in the absorption spectrum for the $o$-tolidine-treated filter paper, a NearInfrared System was used. The experimental tobacco-curing barn where the burner exhaust gas and atmospheric air are introduced and mixed was prepared for comparison of the present method with a reference method. The true $\mathrm{NO}_{2}$ level of exhaust gas in the experimental tobacco-curing barn was measured by a chemiluminescence analyzer (Model 42, Thermo-Environmental Instruments, Inc.).

Table 1. Standard $\mathrm{NO}_{\mathrm{x}}$ used for determining the calibration line

\begin{tabular}{lccc}
\hline $\mathrm{NO}_{\mathrm{x}}$ level, ppm & $\mathrm{NO}_{2}$ level, ppm & NO level, ppm & $\mathrm{N}_{2}$ \\
\hline 4.690 & 0.230 & 4.460 & Balance \\
2.738 & 0.188 & 2.550 & Balance \\
1.334 & 1.296 & 0.038 & Balance \\
1.179 & 0.117 & 1.062 & Balance \\
0.854 & 0.110 & 0.744 & Balance \\
\hline
\end{tabular}




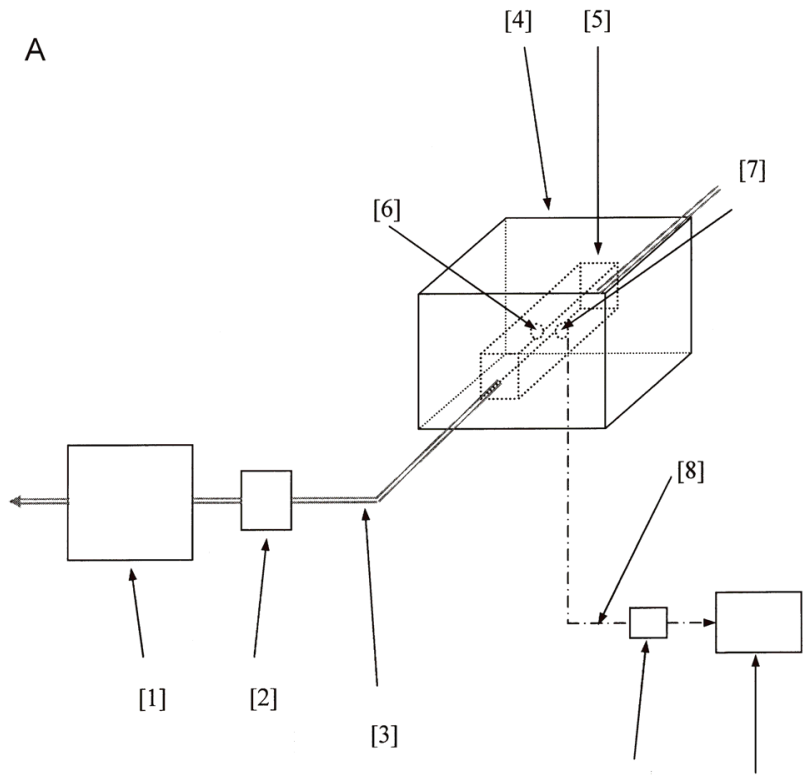

[9]

B

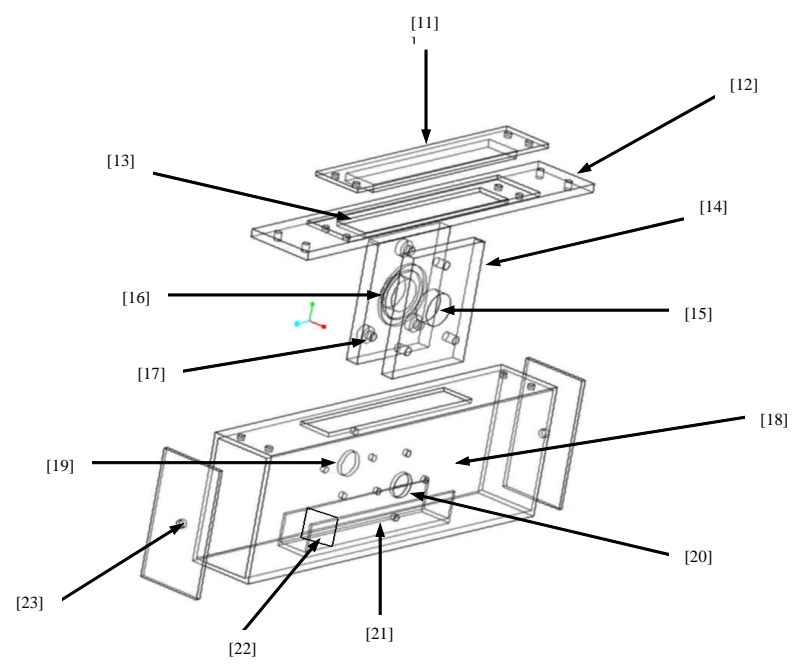

Figure 1. Schematic diagram of the opto-electronic system for measuring ppb-level $\mathrm{NO}_{2}(\mathrm{~A})$; detailed figure of main body [5] (B): [1] pump; [2] flow-meter; [3] direction of flow of NO2;, [4] box for black; [5] main body; [6] LED; [7] phototransistor; [8] signal flow; [9] signal conditioning circuitry; [10] signal display; [11] lid; [12] metal piece for building up the top of the main body, and providing a seat of the lid; [13] opening for the sensor holder; [14] sensor holder; [15] hole for the diffusion of nitrogen dioxide gas; [16] Oring; [17] place for screw; [18] box for the flow of nitrogen dioxide gas, and equipped by opto-electronic system; [19] place for LED; [20] place for phototransistor; [21] binder for fixing the sensor holder; [22] guide; [23] hole for the flow of $\mathrm{NO}_{2}$

\section{Opto-electronic system for measuring ppb-level $\mathrm{NO}_{2}$}

The newly designed system, diagramed in Figures $1 \mathrm{~A}$ and 1B, comprised three parts: 1) a sampling part for introducing $\mathrm{NO}_{2}$ into the main body [5], 2) a sensor holder for the color reaction, and 3 ) an opto-electronic detector to measure the color change on the sensor.
To increase the instrument sensitivity to $\mathrm{NO}_{2}$, the sample gas is forced through the main body of the device by a small pump. As a result, the diffusivity of $\mathrm{NO}_{2}$ gas through the opening [15] of the sensor holder can be increased. The detailed components of this part consist of a pump [1], flowmeter [2], main body [5], tubes, and side-holes of the main body [23]. The pump is set downstream from the main body to pull the $\mathrm{NO}_{2}$ through the main body to prevent contamination by the pump. The gas flow direction is shown by symbol [3], Figure 1A. Because the flow-rate during sampling affects the intensity of the sensor color change, the flow-meter for constant flow of sample gas must be set prior to the pump. Also, the pattern of gas flow inside the main body affects sensitivity, so enough space for the flow of sample gas between the sensor holder [14] and cylinder bars with small hole for fixing LED [6] or phototransistor [7] is necessary. It is important that openings such as [13], [19] and [20] in the main body be completely protected from air leaks. Because the pump draws the $\mathrm{NO}_{2}$ for sampling into the main body, an air leak causes the contamination of sample gas by environmental air outside the room for test. Therefore, the top of the main body is built up by another piece of metal [12] to originally remove air leaks problem from the instrument. It is tightly fixed on the top with a gasket for sealing by screws. The lid [11] of the main body is specially designed for sealing the overlapping structure with a metal piece [12], and screwed tight during test. The small holes for fixing LED and phototransistor in cylinder bars must also be sealed.

Next, the sensor holder [14] in this instrument is designed to support the sensor, promote the color reaction on the sensor by the $\mathrm{NO}_{2}$ diffusion through both side holes, and provide a pathway for light emitted from the LED for the detection of color change. Also, the size of this holder is necessary for convenience when installing the sensor and placing the holder in the box [18] through its opening [13]. The O-ring [16] between both sides of the holder is compressed by screws [17] so that the color reaction on the sensor is caused by no other $\mathrm{NO}_{2}$ flow except the perpendicular diffusion-flow through holes [15] of both sides of the holder. The binder [21] is used for fixing the sensor holder [14] inside the box [18], and the guide [22] is used to align the centerlines between sensor holder holes [15] and box holes $[19,20]$.

Finally, the color change caused by the $\mathrm{NO}_{2}$-sensor reaction is quantified by the opto-electronic detector with its LED [6] and phototransistor [7]. Monochromatic light at wavelength $470 \mathrm{~nm}$ and fixed intensity is generated by LED, penetrates through the treated paper, and is finally detected by the phototransistor. This signal [8] is amplified and conditioned by signal conditioning circuitry [9] before being displayed on the LCD [10]. Fundamental to the development of this device was the determination of the optimum wavelength of light from the LED that would provide the greatest sensitivity to the color change. During development of the device, experiments were conducted to determine the optimum wavelength. For example, with $o$ tolidine as the reagent, Figure 2 shows that light with wavelength of about $430 \mathrm{~nm}$ is most sensitive to the color change. Furthermore, the device must be shielded from external light to eliminate extraneous noise to the optoelectronic system. The duplicate box [4] outside the main body [5] is used to prevent penetration of external light. 


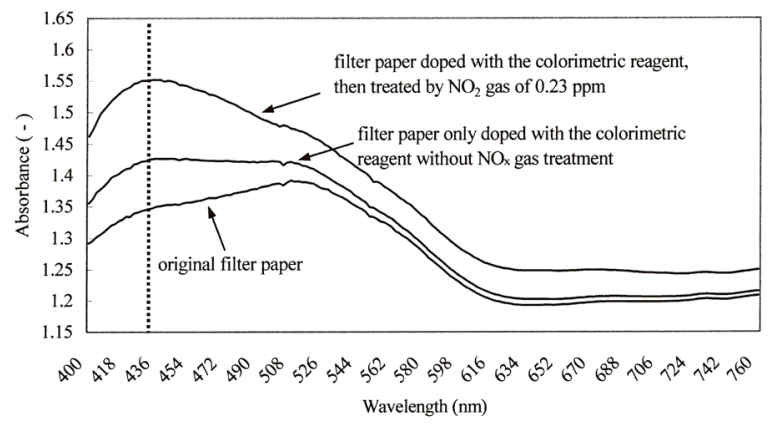

Figure 2. Visible-light absorption spectra of three kinds of filter paper

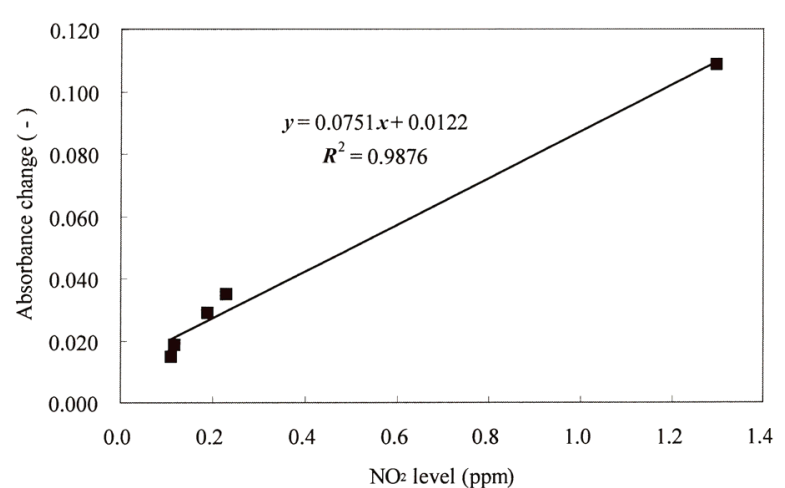

Figure 3. Calibration line for determining $\mathrm{NO}_{2}$ level in the sampling gas with the opto-electronic system protocol

\section{Results and discussion}

To utilize the system, the calibration line of $\mathrm{NO}_{2}$ was determined. A single sheet of $o$-tolidine-treated filter paper was exposed for $10 \mathrm{~min}$ to several different concentrations of $\mathrm{NO}_{2}$, flow-rate $1000 \mathrm{cc} / \mathrm{min}$. The absorbance change of monochromatic light (defined as the difference between the absorbance of unexposed treated filter paper and that of the $\mathrm{NO}_{2}$-exposed treated filter paper) was then calculated by measurement of the intensity of the light traversing the sensor. From this, a corresponding calibration curve (Figure 3) was obtained. This curve shows that the absorbance change is linearly proportional to the $\mathrm{NO}_{2}$ level.

$$
y=0.0751 x+0.0122 \text { with } R^{2}=0.9876
$$

where $y=$ absorbance change of the sensor, $x=\mathrm{NO}_{2}$ level. Not only can the calibration line define the concentration of $\mathrm{NO}_{2}$ in the sample but also the real-time monitoring of the ppb-level $\mathrm{NO}_{2}$ in the field can be accomplished.

An experimental burner-equipped tobacco-curing barn was employed to compare results from the currently described system with those from the chemiluminescence analyzer. The sample gases were introduced continuously into the instrument for $10 \mathrm{~min}$ at a flow-rate of $1000 \mathrm{cc} / \mathrm{min}$. To cool the sample gases from the experimental barn, the simple cooler was set prior to the instrument. Even though an attempt was made to fix the $\mathrm{NO}_{2}$ level of sample gases from the chemiluminescence analyzer at a single value for $10 \mathrm{~min}$, it was difficult to do so. Thus, because there were some fluctuations of the values measured by the chemiluminescence analyzer (Figure 4), the average $\mathrm{NO}_{2}$ concentration for $10 \mathrm{~min}$ was employed in the comparison. After comparing those values, Figure 5 showed that some

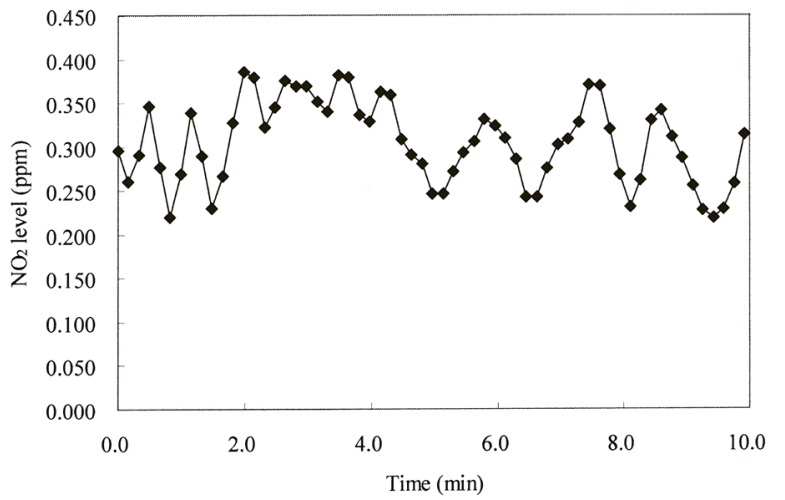

Figure 4. Temporal changes of $\mathrm{NO}_{2}$ levels of the sampling gas from the experimental barn, measured with the chemiluminescence analyzer

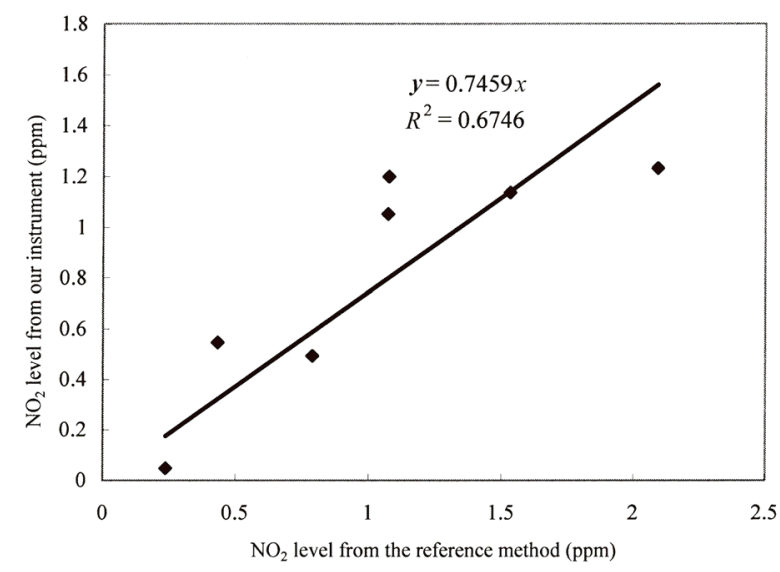

Figure 5. Comparison between $\mathrm{NO}_{2}$ levels (<2.5 ppm) measured by the instrument described herein and the chemiluminescence analyzer reference method

differences occur between the methods, especially at an $\mathrm{NO}_{2}$ level greater than $1.5 \mathrm{ppm}$. It is considered that those results are produced by the following two factors: 1) An $\mathrm{NO}_{2}$ level higher than $1.5 \mathrm{ppm}$ is beyond the range of the calibration line. 2) Because the colorimetric reagent, $o$ tolidine, on the filter paper should be entirely consumed within 10 min by $\mathrm{NO}_{2}$ at a level greater than $1.5 \mathrm{ppm}$, there is no further color reaction on the sensor to cause the underestimate. Even though standard $\mathrm{NO}_{\mathrm{x}}$ with an $\mathrm{NO}_{2}$ level higher than $1.5 \mathrm{ppm}$ was not directly employed to determine the reason, temporal reduction on the slope of absorbance changes continuously measured on the single filter paper impregnated with $5 \mathrm{~g} / \mathrm{L}$ of $o$-tolidine in ethanol (Figure 6) indirectly showed the reason. Therefore, it is necessary to prepare sensors with higher concentrations of $o$ tolidine to measure $\mathrm{NO}_{2}$ levels above $1.5 \mathrm{ppm}$. Figure 7 , except for two data points with $\mathrm{NO}_{2}$ levels greater than 1.5 ppm, showed better agreement between them. Thus, it indicated that $\mathrm{NO}_{2}$ at ppb-level was successfully measured by the method and device described herein.

\section{Conclusions}

By detecting color change induced by $\mathrm{NO}_{2}$ on filter paper impregnated with the colorimetric reagent $o$-tolidine, it was found that $\mathrm{NO}_{2}$ could successfully be detected. The 


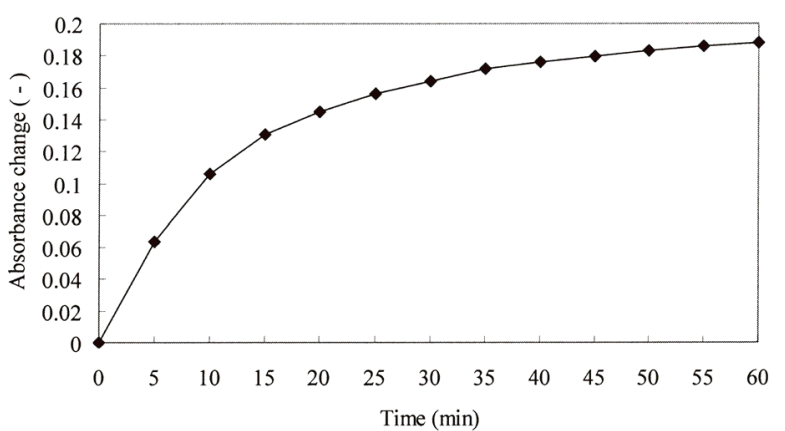

Figure 6. Temporal changes of absorbance continuously measured on a single filter paper impregnated with o-tolidineethanol solution $(5 \mathrm{~g} / \mathrm{L})$ by the instrument described herein into which $1.296 \mathrm{ppm} \mathrm{NO}$ flowed at $1000 \mathrm{cc} / \mathrm{min}$

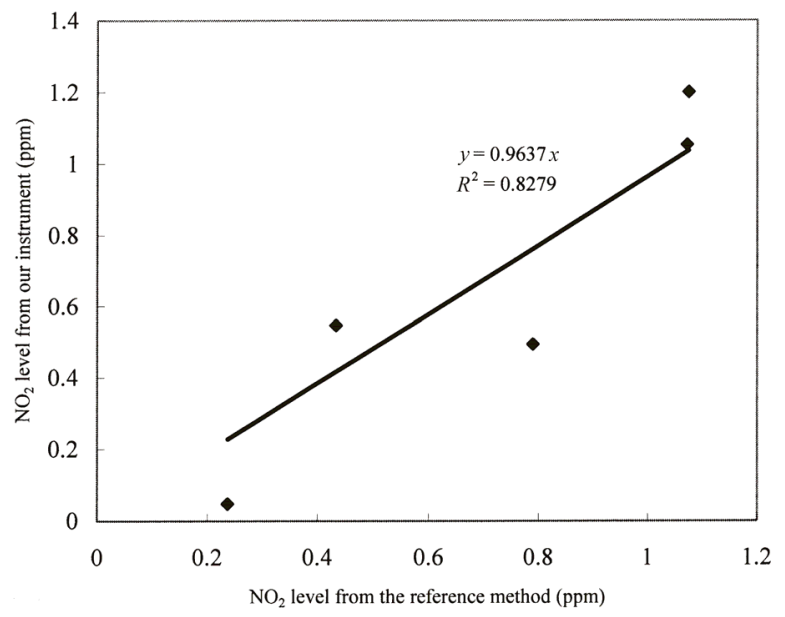

Figure 7. Comparison between $\mathrm{NO}_{2}$ levels (<1.5 ppm) measured by the instrument described herein and the chemiluminescence analyzer reference method

calibration line between $\mathrm{NO}_{2}$ levels and absorbance changes at peak wavelength showed good linear relationships which indicate the possibility of measuring ppb-level $\mathrm{NO}_{2}$. Also, it was found that after comparison between $\mathrm{NO}_{2}$ concentrations inside the experimental tobacco-curing barn measured by the method described herein and by the chemiluminescence analyzer, $\mathrm{NO}_{2}$ at a ppb-level was successfully measured. Thus, in this study, a low-cost optoelectronic system for efficiently measuring ppb-level $\mathrm{NO}_{2}$ in environmental air or exhaust gases by colorimetry was developed.

\section{OPTIMIZATION OF THE SYSTEM}

As described above, a low-cost opto-electronic system for efficiently measuring ppb-level $\mathrm{NO}_{2}$ in environmental air or exhaust gas by colorimetry was developed. Prior to application to the field test, the next step was to identify those adjustable factors affecting the reproducibility and life-time of the sensor (the $o$-tolidine-treated filter paper), the measuring capacity, the continuous measurement, and the sensitivity of the sensor. To increase those capacities of the device, the identified factors must be simultaneously optimized. From them, several adjustable factors such as

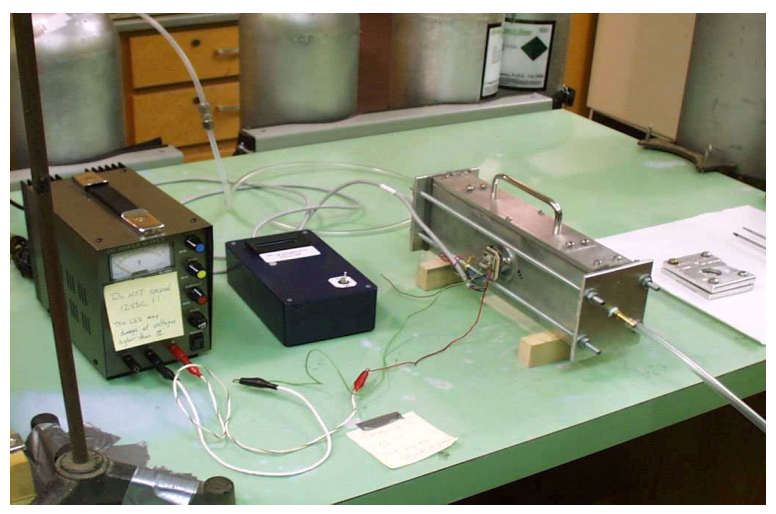

Figure 8. Opto-electronic system for determining $\mathrm{NO}_{2}$ level

deviation among the sensors produced by the same method, lifetime of the sensor, concentration of colorimetric reagent in the solution, dipping time of filter paper in the solution, sampling time, and sampling flow-rate were ascertained. Additionally, the effect on sensitivity of the NO level in the sample gas needed to be determined.

\section{Materials and methods}

Sensors were prepared with Whatman filter paper and $o$ tolidine concentrations of $3 \mathrm{~g} / \mathrm{L}, 5 \mathrm{~g} / \mathrm{L}, 10 \mathrm{~g} / \mathrm{L}$, and $20 \mathrm{~g} / \mathrm{L}$ as described above. As before, the $o$-tolidine-treated filter paper was dried under reduced pressure at room temperature but various drying periods were used. Each sensor was then stored in the dark. The standard $\mathrm{NO}_{\mathrm{x}}$ was that described in Table 1.

In this phase of the study, the effect of a voltage adjuster of power to the LED with an upper 12-V limit to emit the light with a wavelength of $470 \mathrm{~nm}$ attached to the optoelectronic system (Figure 8) for $\mathrm{NO}_{2}$ detection was tested as was the volumetric flow controller of $\mathrm{NO}_{\mathrm{x}}$ from the cylinder.

\section{Results and discussion}

Reproducibility and life-time of the chemical sensor: To determine the reproducibility of the sensors, they were impregnated with a $20 \mathrm{~g} / \mathrm{L}$ ethanol solution of $o$-tolidine for $10 \mathrm{~min}$, and then their initial light intensities were measured by the LED (input power, $10 \mathrm{~V}$ ) and phototransistor. After 10-min exposure to $0.230 \mathrm{ppm} \mathrm{NO}_{2}$ at a flow-rate of $1000 \mathrm{cc} / \mathrm{min}$, the sensitivity of the sensors was measured in the system. Figure 9 depicts the results obtained with 10 similarly prepared sensors. The relative standard deviation of response $(n=10)$ as an index of reproducibility was $6.8 \%$ for the initial light intensity, $10.3 \%$ for the sensor sensitivity. The initial light intensity of the sensor is related to the amount and uniformity of the impregnated colorimetric reagent in the sensor, and so its higher reproducibility is very important to finally raise the reproducibility of the sensitivity.

Several tests on the change in reproducibility of the sensitivity of the sensor with time were conducted to determine its life-time. Similarly prepared sensors were stored in a vinyl bag in the dark under other room conditions. Their sensitivities were measured day by day at two levels of 


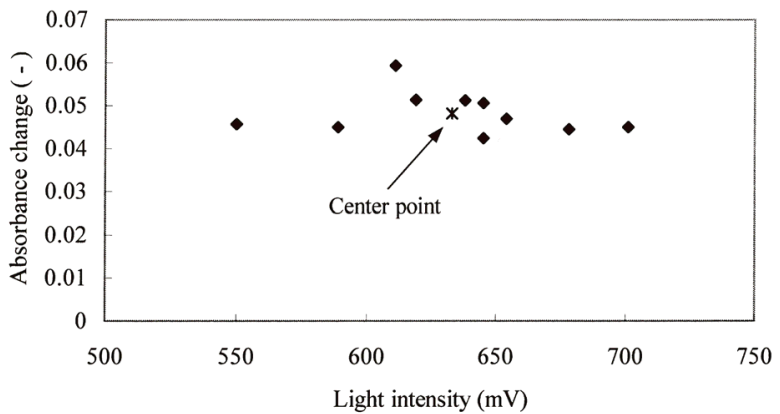

Figure 9. Distribution of the initial light intensities of 10 similarly prepared chemical sensors and their sensitivities when exposed to $0.230 \mathrm{ppm} \mathrm{NO}$, flow rate $1000 \mathrm{cc} / \mathrm{min}$

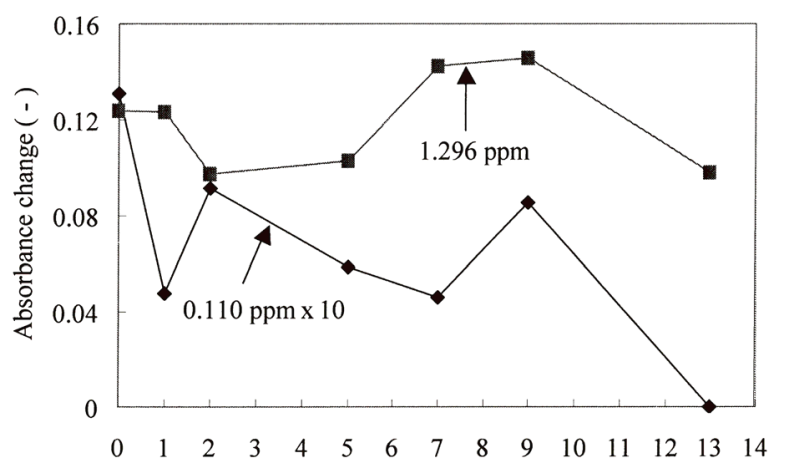

Period for the test (days)

Figure 10. Temporal changes of the sensitivities of stored chemical sensors

$\mathrm{NO}_{2}, 0.110 \mathrm{ppm}$ and $1.296 \mathrm{ppm}$. The results (Figure 10) show that the sensitivities of sensors stored in a vinyl bag were unstable, especially those at $0.110 \mathrm{ppm} \mathrm{NO}_{2}$. They became quite unstable in one day. It was considered that the long-term exposure of sensors to $\mathrm{NO}_{2}(8-30 \mathrm{ppb})$ included in the vinyl bag or the $\mathrm{NO}_{2}$ that penetrated the bag film from environmental air lowered their sensitivities at particularly low $\mathrm{NO}_{2}$ concentrations. Therefore, a machine and film for vacuum packaging were employed to protect the sensors from exposure to environmental $\mathrm{NO}_{2}$ during long-term storage. This resulted in sensitivity stability for about 9 days after $o$-tolidine treatment. Even though the sensitivity of the sensor exposed to $1.296 \mathrm{ppm} \mathrm{NO}_{2}$ was maintained well after 9 days, that at $0.110 \mathrm{ppm} \mathrm{NO}_{2}$ disappeared (Figure 10). Also, the variance of sensitivities at lower $\mathrm{NO}_{2}$ concentrations was much greater than that at higher $\mathrm{NO}_{2}$ concentrations for the same period.

Capacity on upper detection limit, continuous measurement and sensitivity of the sensor: In this phase of the study, an attempt was made to increase not only the sensitivity of the sensor but also its capacity for upper detection limit and continuous measurement. In fact, because the two are not proportional, they should be optimized for practical purposes. To increase the sensor capacity for upper detection limit and continuous measurement, the $o$-tolidine level in the sensor should be raised by increasing the $o$ tolidine solution concentration and dipping time of the sensor into the solution or by decreasing the time interval of ethanol removal from the sensors and the sample gas flow-rate.
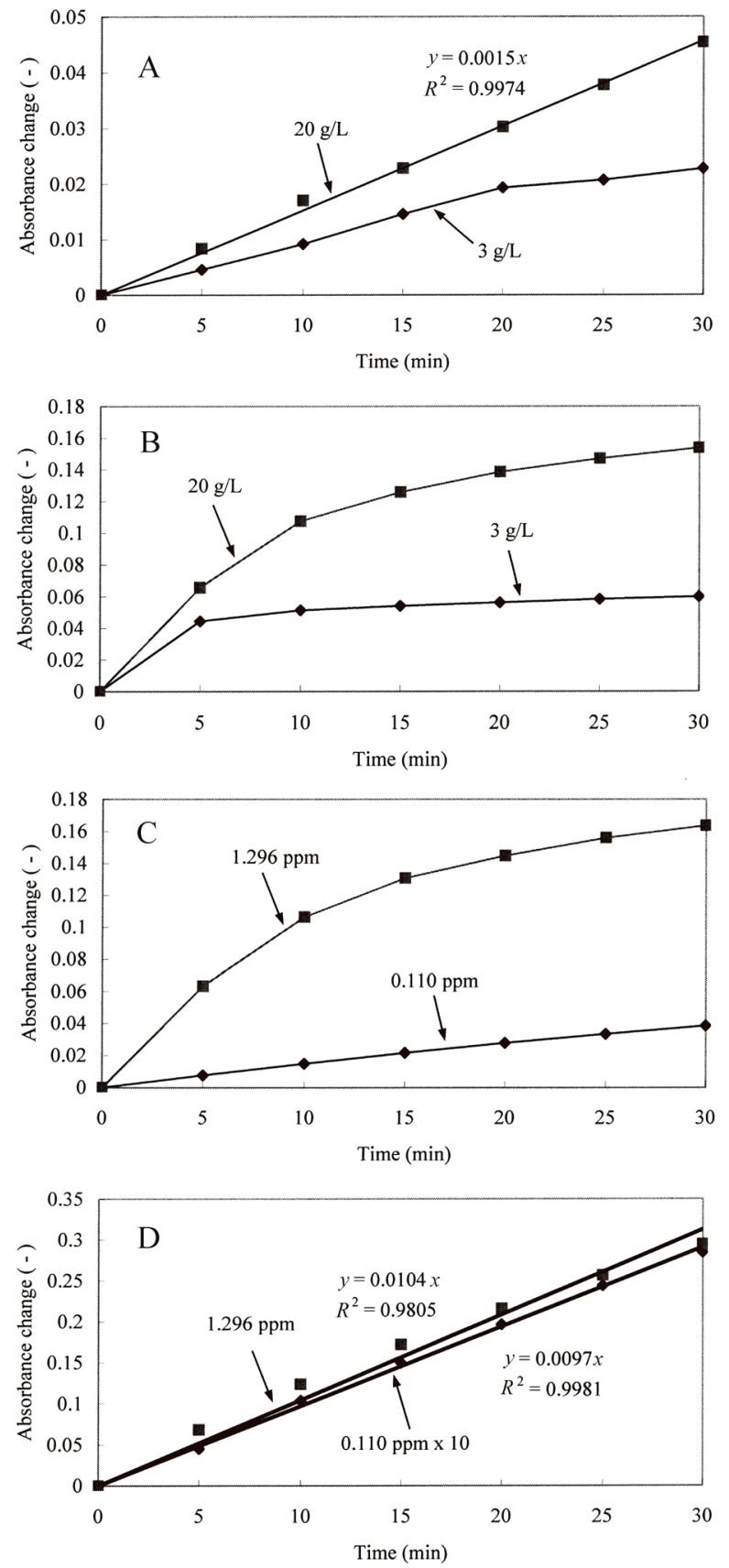

Figure 11. Temporal changes of absorbance changes of sensors treated with two concentrations $(3 \mathrm{~g} / \mathrm{L}, 20 \mathrm{~g} / \mathrm{L})$ of 0 -tolidine solution for $10 \mathrm{~min}$, dried for $40 \mathrm{~min}$, then exposed to (A) 0.110 ppm NO , flow-rate $1000 \mathrm{cc} / \mathrm{min}$; (B) 1.296 ppm NO , flow-rate $1000 \mathrm{cc} / \mathrm{min}$; (C) treated with o-tolidine solution $(20 \mathrm{~g} / \mathrm{L})$ for 5 min, dried for $40 \mathrm{~min}$, then exposed to $0.110 \mathrm{ppm}$ and 1.296 ppm $\mathrm{NO}_{2}$, flow-rate $1000 \mathrm{cc} / \mathrm{min}$; (D) treated with o-tolidine solution $(20 \mathrm{~g} / \mathrm{L})$ for $10 \mathrm{~min}$, dried for $20 \mathrm{~min}$, then exposed to $0.110 \mathrm{ppm}$ and $1.296 \mathrm{ppm} \mathrm{NO}{ }_{2}$, flow-rate $1000 \mathrm{cc} / \mathrm{min}$

1) As seen in Figures $11 \mathrm{~A}$ and $11 \mathrm{~B}$, sensors treated with the higher concentration $o$-tolidine solution $(20 \mathrm{~g} / \mathrm{L})$ showed higher sensitivity. Obviously, sensors treated with the higher concentration solution of $o$-tolidine have more $o$-tolidine to react with $\mathrm{NO}_{2}$. Thus, the higher sensitivity sensor provides the equipment with a more stable sensitivity for detecting higher levels of $\mathrm{NO}_{2}$. It was deduced that the capacity of the sensor for upper detection limit and continuous measurement is dependent on the $o$-tolidine concentration in the solution. 


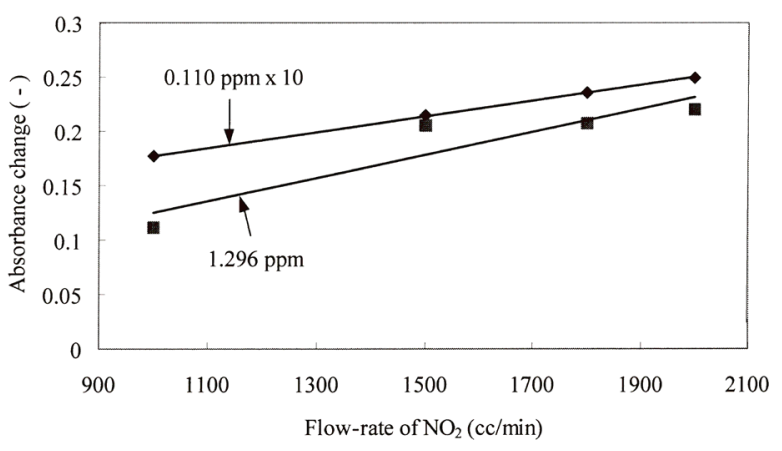

Figure 12. Absorbance changes of sensors treated with 0 tolidine solution $(20 \mathrm{~g} / \mathrm{L})$ for $10 \mathrm{~min}$, dried for $40 \mathrm{~min}$, then exposed for $10 \mathrm{~min}$ to $0.110 \mathrm{ppm}$ and $1.296 \mathrm{ppm} \mathrm{NO}$ at various flow-rates

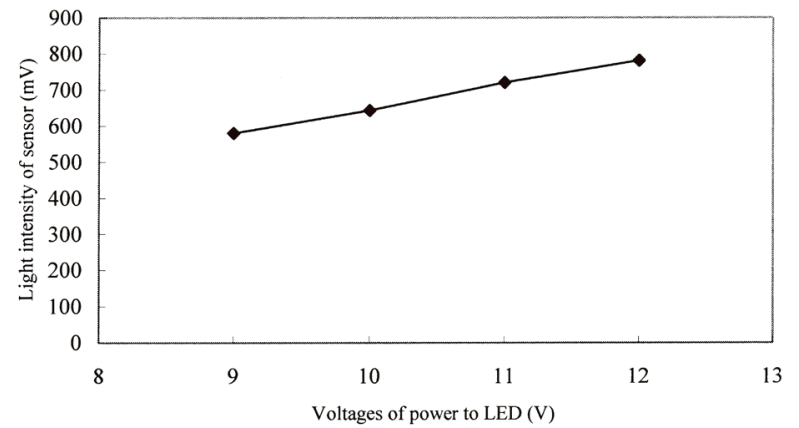

Figure 13. Relationship between power voltage to LED and initial light intensity of the sensor

2) The dipping time of the sensor in the solution during its preparation little affected the capacity of the sensor on upper detection limit and continuous measurement (compare Figures $11 \mathrm{~A}, 11 \mathrm{~B}$, and $11 \mathrm{C}$ ). It is assumed that the sensor could be saturated by the solution within $5 \mathrm{~min}$. If the $\mathrm{NO}_{2}$ level is measured once, not continuously by our meter, Figures $11 \mathrm{~B}$ and $11 \mathrm{C}$ indicate that the optimum sampling time for each test is $10 \mathrm{~min}$ within which time the temporal changes maintain linearity even at a flow of $1.296 \mathrm{ppm} \mathrm{NO}_{2}$. 3 ) The time interval of ethanol evaporation from the sensors under reduced pressure was quite important to measure $\mathrm{NO}_{2}$ level continuously. In Figure 11D, both temporal changes at 20-min drying time showed much better linearity than those in Figures $11 \mathrm{~B}$ and $11 \mathrm{C}$ at 40 min drying time. The calculated absorbance changes per unit $\mathrm{NO}_{2}$ concentration and unit time at $0.110 \mathrm{ppm}$ and $1.296 \mathrm{ppm} \mathrm{NO}$ were 0.00882 and 0.00802 (abs/ppm/min), respectively, and the two values were quite close. This indicates that the $\mathrm{NO}_{2}$ level can be continuously measured by the coefficients for at least $30 \mathrm{~min}$.

4) Figure 12 showed that the increase of flow-rate of $\mathrm{NO}_{2}$ raised the level of sensitivity of sensors as expected. However, because this increase consumes much of the sensor $o$-tolidine, the lower flow-rate of sample $\mathrm{NO}_{2}$ is considered to be better for increasing the sensor capacity on upper detection limit and continuous measurement. It was reported that the diffusion resistance of $\mathrm{NO}_{2}$ through the gas film could be neglected for a gas flow-rate greater than $300 \mathrm{cc} / \mathrm{min}$ (7). However, because the $\mathrm{NO}_{2}$ flow in the experimental prototype was unstable at a flow-rate below $1000 \mathrm{cc} / \mathrm{min}$, the optimum flow-rate for the current device was considered to be $1000 \mathrm{cc} / \mathrm{min}$.
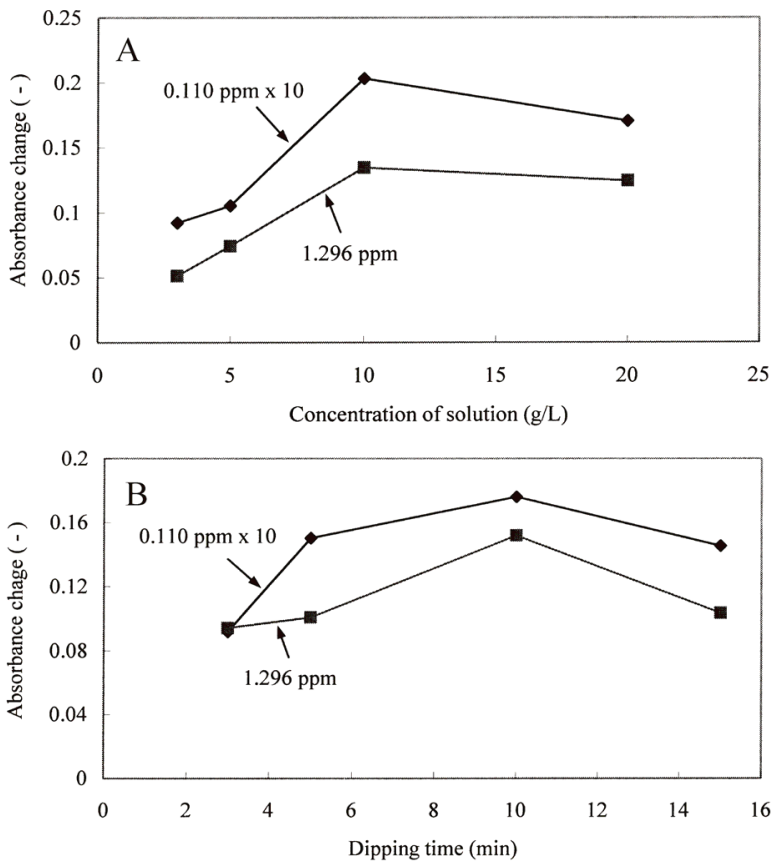

Figure 14. Absorbance changes of sensors treated with (A) various o-tolidine solutions ( $3 \mathrm{~g} / \mathrm{L}, 5 \mathrm{~g} / \mathrm{L}, 10 \mathrm{~g} / \mathrm{L}, 20 \mathrm{~g} / \mathrm{L}$ ) for 10 min; (B) o-tolidine solution $(20 \mathrm{~g} / \mathrm{L})$ for various dipping times, dried for $\mathbf{4 0} \mathrm{min}$, then exposed for $10 \mathrm{~min}$ to $0.110 \mathrm{ppm}$ and $1.296 \mathrm{ppm} \mathrm{NO}$, flow-rate of $1000 \mathrm{cc} / \mathrm{min}$

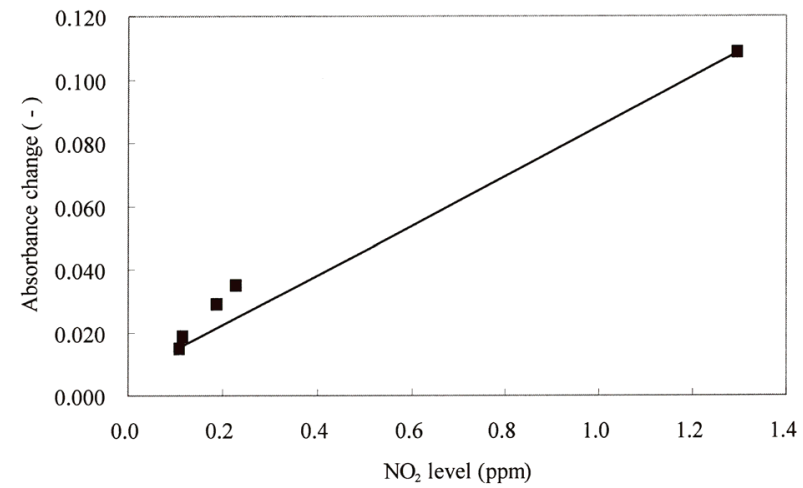

Figure 15. Effects of NO on instrument sensitivity

In fact, the sensitivity of the instrument described herein is affected mainly by two factors, the opto-electronic part and the sensor. First, the opto-electronic part including the LED and phototransistor strongly affected the instrument sensitivity. In Figure 13, the initial light intensity of the sensor related to the sensitivity was increased proportionally with power voltage to the LED. Otherwise, the concentration of $o$-tolidine in the solution and dipping time of the sensor in the solution also affected the sensitivity of the developed instrument (see Figures 14A and 14B). From them it can be seen that the optimum solution concentration of $o$-tolidine was about $10 \mathrm{~g} / \mathrm{L}$, the optimum dipping time about $10 \mathrm{~min}$.

NO effect on the sensitivity: To determine the effect of NO on the sensitivity, tests were carried out with standard $\mathrm{NO}_{\mathrm{x}}$ (Table 1). The result (Figure 15) indicated that the other three points with over $1.0 \mathrm{ppm}$ NO were shifted from the line connecting both end-points with relatively less NO. 


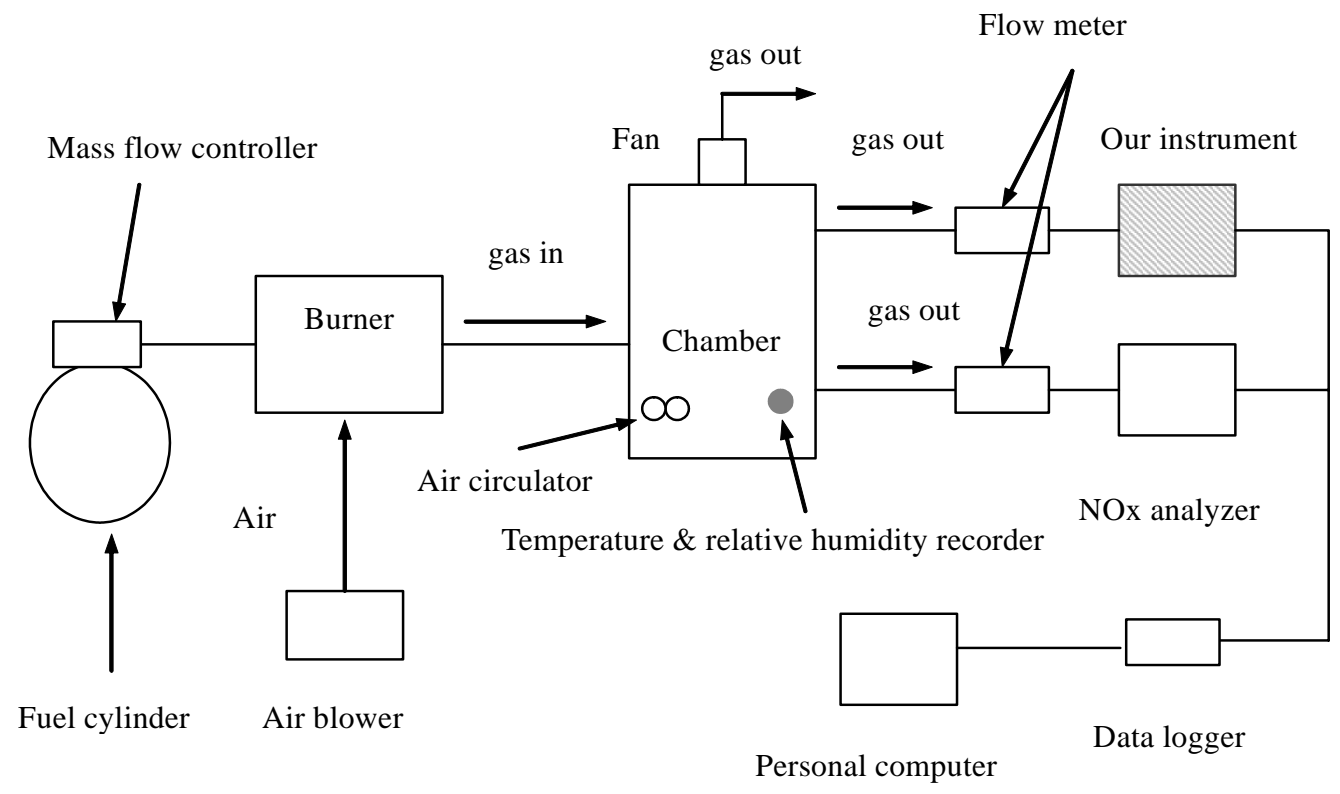

Figure 16. System for measuring effects of temperature and RH on the sensitivity of chemical sensors in the artificial environment

The magnitude of variation between them was proportional to the NO in each standard. This indicates that the instrument sensitivity was only slightly affected by NO. However, because the $\mathrm{NO}_{x}$ (which included about $1.0 \mathrm{ppm} \mathrm{NO}$ ) showed a sensitivity change of less than 0.005 , it was concluded that NO has little effect on the results obtained with the instrument described herein when it is used to monitor low-level $\mathrm{NO}_{\mathrm{x}}$.

\section{Conclusions}

This phase of the study involved the determination of the adjustable factors that affect the reproducibility and lifetime of the sensor (the $o$-tolidine-treated filter paper), the measuring capacity, the continuous measurement, and the sensor sensitivity. Also, the identified factors were simultaneously optimized to increase those capacities of the device. The relative standard deviation of response $(n=10)$ as an index of reproducibility was $6.8 \%$ for the initial light intensity and $10.3 \%$ for the sensor sensitivity. About the life-time of the sensor packed by the vacuum machine, the sensor sensitivity at $1.296 \mathrm{ppm} \mathrm{NO}_{2}$ was maintained well after 9 days, but that at $0.110 \mathrm{ppm} \mathrm{NO}_{2}$ disappeared. Also, the variance of sensitivities under lower concentration of $\mathrm{NO}_{2}$ was much greater than that under higher concentration of $\mathrm{NO}_{2}$ over the same period.

It was found that the sensor capacity for upper detection limit and continuous measurement is dependent on the $o$ tolidine solution concentration. However, the time of dipping the sensor into the solution little affected the sensor capacity for upper detection limit and continuous measurement. The optimum sampling time for each test is $10 \mathrm{~min}$ during which the temporal changes maintain linearity even at a flow of $1.296 \mathrm{ppm} \mathrm{NO}_{2}$. Also, the time interval of ethanol removal from the sensors under reduced pressure was quite important to the continuous measurement of $\mathrm{NO}_{2}$ level. The increase of sampling flow-rate of $\mathrm{NO}_{2}$ raised the level of sensitivity of sensors as expected.

With regard to the sensitivity of the instrument, the optimum concentration of $o$-tolidine in the solution was about $10 \mathrm{~g} / \mathrm{L}$, the optimum dipping time was about $10 \mathrm{~min}$. Additionally, the level of NO included in the sampling gas affected its sensitivity only slightly with noise less than 0.005 .

\section{CHARACTERISTICS OF THE CHEMICAL SENSOR FOR MEASURING ppb-NO $\mathrm{NO}_{2}$ BY COLORIMETRY}

In this phase of the study, the characteristics of the sensors used in the opto-electronic system described in the sections above were determined. Tests on the life-time of the sensor preserved in a vacuum package indicated its optimum lifetime was about 9 days. In addition, the relative standard deviation of absorbance changes of the sensors at lower $\mathrm{NO}_{2}$ concentration was greater than that at higher $\mathrm{NO}_{2}$ concentration during storage, because the sensors could be continuously contaminated by ambient $\mathrm{NO}_{2}$. After the vacuum package of sensors was opened for field tests, the sensitivities of the sensors subsequently stored in a vinyl bag were well maintained for at least $6 \mathrm{~h}$. The effects of temperature and relative humidity $(\mathrm{RH})$ on the sensitivity of the sensor were found to be negative. To apply the instrument described herein to the tobacco-curing process, the optimized coefficient of the calibration line for it was determined. Comparison of $\mathrm{NO}_{2}$ levels between a reference method and the method described herein indicated good agreement. Also, even though temperature and $\mathrm{RH}$ in each phase of the tobacco-curing process varied widely, those phases had a similar coefficient on their calibration lines.

\section{Materials and methods}

The sensor (filter paper, $o$-tolidine solution, $20 \mathrm{~g} / \mathrm{L}$ ) was prepared as described above. It was packed by a vacuum machine, then stored in the dark. Commercial-grade $\mathrm{NO}_{x}$ (National Specialty Gases, Raleigh, NC) was used as the standard (Table 1). To determine the effects of temperature and RH on the sensitivity of the sensor, the system in Figure 16 was developed to measure the effects in the artificial environment. The environment in the experimental chamber 


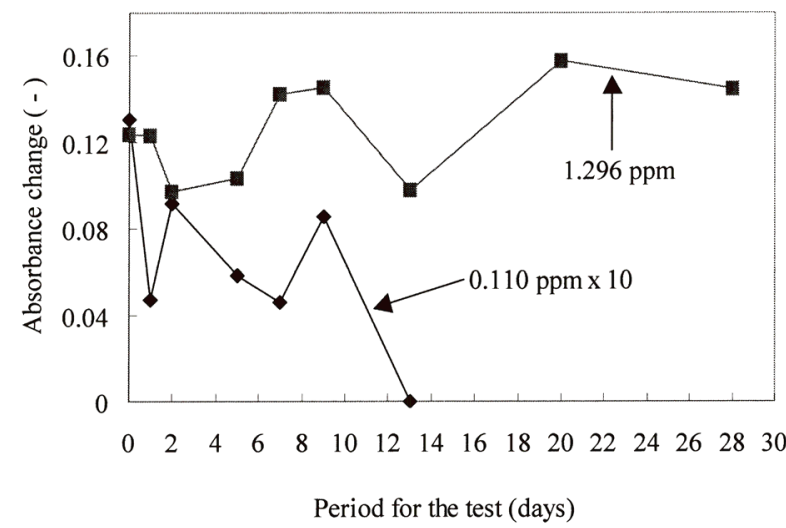

Figure 17. Temporal changes of the sensitivities of stored chemical sensors

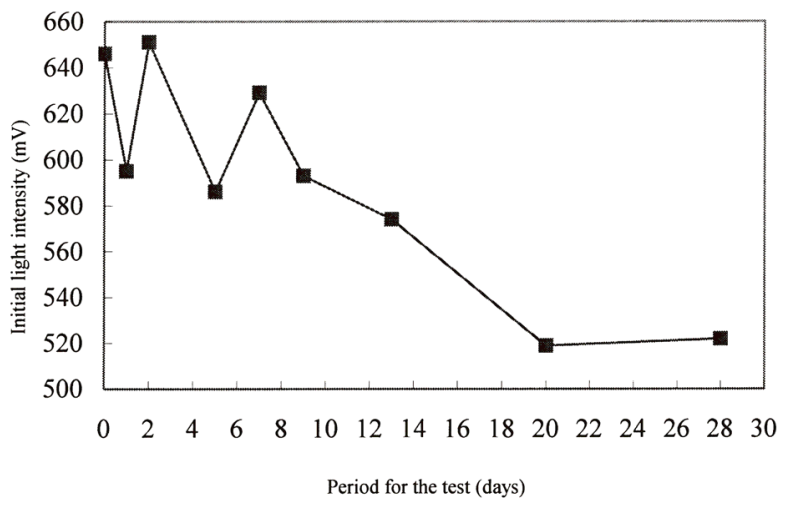

Figure 18. Temporal changes during storage of the initial light intensities of similarly prepared chemical sensors

was controlled during introduction of the exhaust gas from the burner by means of a temperature and RH controller. Here, propane was the burner fuel. The $\mathrm{NO}_{2}$ level in the chamber was adjusted by a flow controller attached to the fuel cylinder and an air blower below the burner. The $\mathrm{NO}_{2}$ level in the chamber was monitored with a chemiluminescence analyzer (Model 42, Thermo-Environmental Instruments, Inc.) as a reference method to the instrument described herein. Temperature and $\mathrm{RH}$ were recorded. However, the average $\mathrm{NO}_{2}$ level measured by the chemiluminescence analyzer was applied for its comparison to our instrument, because those data from inside the chamber actually fluctuated.

\section{Results and discussion}

Life-time of the chemical sensor: Similarly prepared sensors were stored in darkness under room conditions and two storage conditions: in a vinyl bag with and without vacuum Their sensitivities were measured daily with the newly developed instrument described herein at two $\mathrm{NO}_{2}$ levels $(0.110 \mathrm{ppm}$ and $1.296 \mathrm{ppm})$, flow-rate $1000 \mathrm{cc} / \mathrm{min}$, 10 -min exposure. Because of their continuous exposure to environmental $\mathrm{NO}_{2}$ (8 to $30 \mathrm{ppb}$ ), the sensitivities of sensors stored in the vinyl bag without vacuum rapidly disappeared in a day in the experiments with $0.110 \mathrm{ppm} \mathrm{NO}_{2}$. However, the sensitivities of sensors stored in vacuum lasted at least 9 days for $0.110 \mathrm{ppm} \mathrm{NO}_{2}$. Useable sensitivities lasted about a month at $1.296 \mathrm{ppm} \mathrm{NO}_{2}$ (Figure 17).
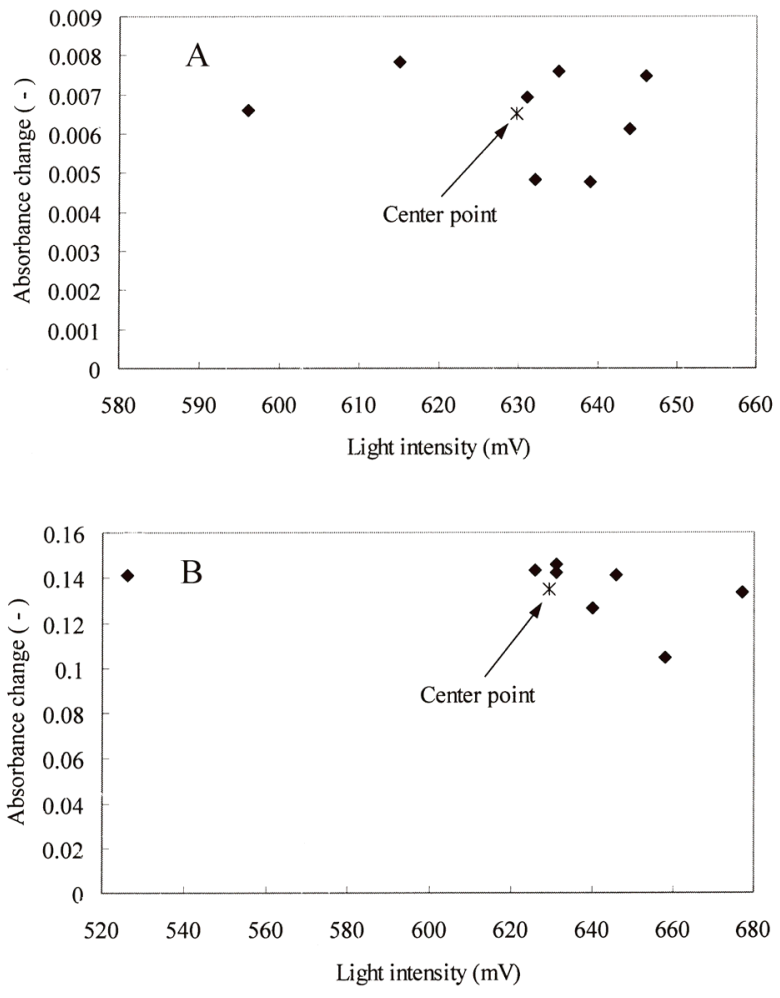

Figure 19. Distribution of initial light intensities of similarly prepared chemical sensors and their sensitivities when exposed to $0.110 \mathrm{ppm} \mathrm{NO} \mathrm{N}_{2}(\mathrm{~A})$ and $1.296 \mathrm{ppm} \mathrm{NO}_{2}(B)$

Calculation of the relative standard deviation of absorbance change as an index of reproducibility (Figure 17 ) gave a value $(n=5)$ for $0.110 \mathrm{ppm} \mathrm{NO} \mathrm{NO}_{2}$ of $32.4 \%$ and a value $(n=$ 9) for $1.296 \mathrm{ppm} \mathrm{NO}_{2}$ of $18.0 \%$. The sensors showed higher instability over time for detecting lower $\mathrm{NO}_{2}$ concentration because of their long-term exposure to environmental $\mathrm{NO}_{2}$. Also, arithmetically the deviation for lower $\mathrm{NO}_{2}$ concentration should be more sensitive, assuming the same measuring error. Of the values noted above, the relative standard deviation for $0.110 \mathrm{ppm} \mathrm{NO}_{2}$ excluded the initial and final data because of their wide deviation from the average. Therefore, to maintain satisfactory sensitivity of sensors under low $\mathrm{NO}_{2}$ concentration, it is recommended that only those sensors stored between 1 and 9 days be used. Figure 18 showed that the initial light intensity of sensors prior to $\mathrm{NO}_{2}$ treatment continuously decreased with time during storage. This phenomenon is probably caused by long-term exposure to environmental $\mathrm{NO}_{2}$.

For comparison, each initial relative standard deviation of absorbance change at $0.110 \mathrm{ppm}$ and $1.296 \mathrm{ppm} \mathrm{NO}_{2}$ was determined. The value $(n=8)$ at $0.110 \mathrm{ppm} \mathrm{NO}_{2}$ was $18.3 \%$ (Figure 19A); the value $(n=8)$ at $1.296 \mathrm{ppm} \mathrm{NO}_{2}$ was $10.1 \%$ (Figure 19B). These two relative standard deviations were much lower than values in Figure 17. This indicates that the reproducibility of the sensors was strongly affected by the duration of their storage, especially for detection of lower $\mathrm{NO}_{2}$ concentrations. The linearity between absorbance change of the sensors and time was unstable during their storage, indicating that continuous measurement would be unstable as well. When the absorbance change of the sensors stored in vacuum for 2 days was measured continuously every $5 \mathrm{~min}$ for $30 \mathrm{~min}$ under 


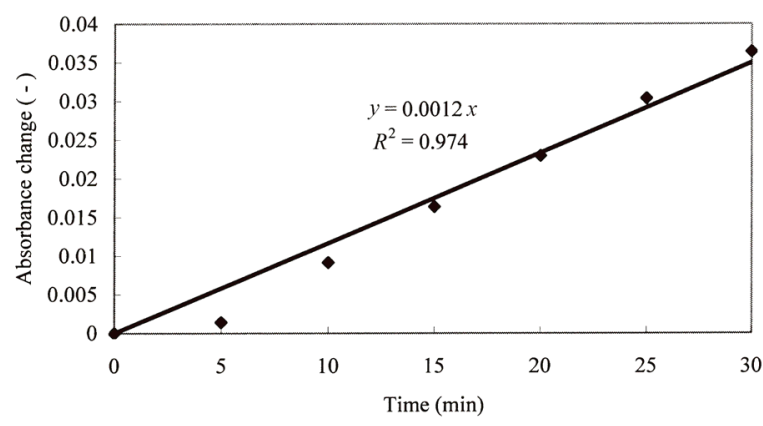

Figure 20. Temporal changes of absorbance change of chemical sensors stored for 2 days, then exposed to 0.110 ppm NO

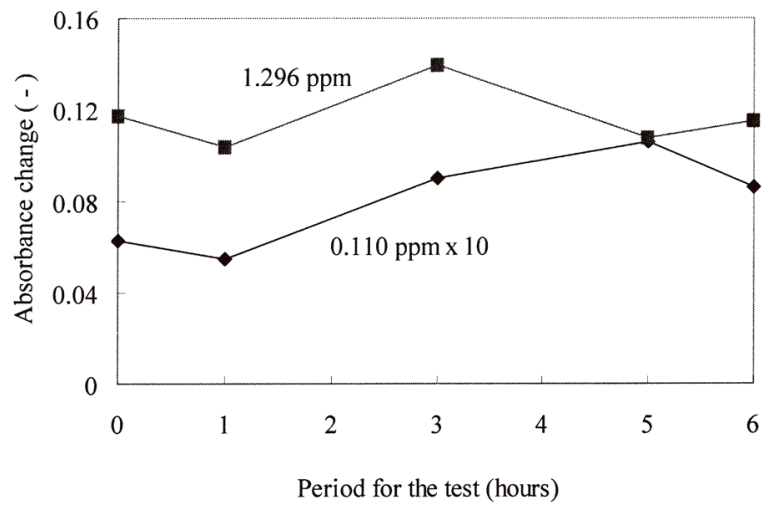

Figure 21. Temporal changes of the sensitivities of chemical sensors stored in a vinyl bag

the flow of $0.110 \mathrm{ppm} \mathrm{NO}_{2}$, a bend between 0 and $10 \mathrm{~min}$ on the sensitivity was observed (Figure 20). This was considered another obstacle to overcome for continuous measurement.

In fact, it is difficult to preserve the sensors in a vacuum package again once the package has been opened for a field test. Therefore, knowledge was required on how long the sensors in the ordinary vinyl bag maintain their sensitivities. It was determined that they were well-maintained for at least $6 \mathrm{~h}$ (Figure 21).

Effects of temperature and relative humidity on the sensitivity of the sensor: Comparison of the data in Figures 22A and $22 \mathrm{~B}$ indicated that the coefficient of regression equation in Figure 22B was larger than that in Figure 22A. This showed that temperature negatively affected the sensitivity of the sensors under the same RH. Also, the coefficient of regression equation for Figure 22B data was larger than that for Figure 22C data. Thus, RH negatively affected the sensitivity of the sensors at the same temperature. That coefficient of Figure 22D data was even larger than the others, because it was determined with standard $\mathrm{NO}_{2}$ levels at lower temperature (room temperature) and no moisture.

Application to the tobacco curing process: The instrument described above was originally developed to determine the $\mathrm{NO}_{2}$ level inside tobacco-curing barns. The tobacco-curing schedule (Figure 23) typically has three phases: yellowing, leaf drying, and stem drying (15). There is considerable difference in temperature and $\mathrm{RH}$ among these tobacco-
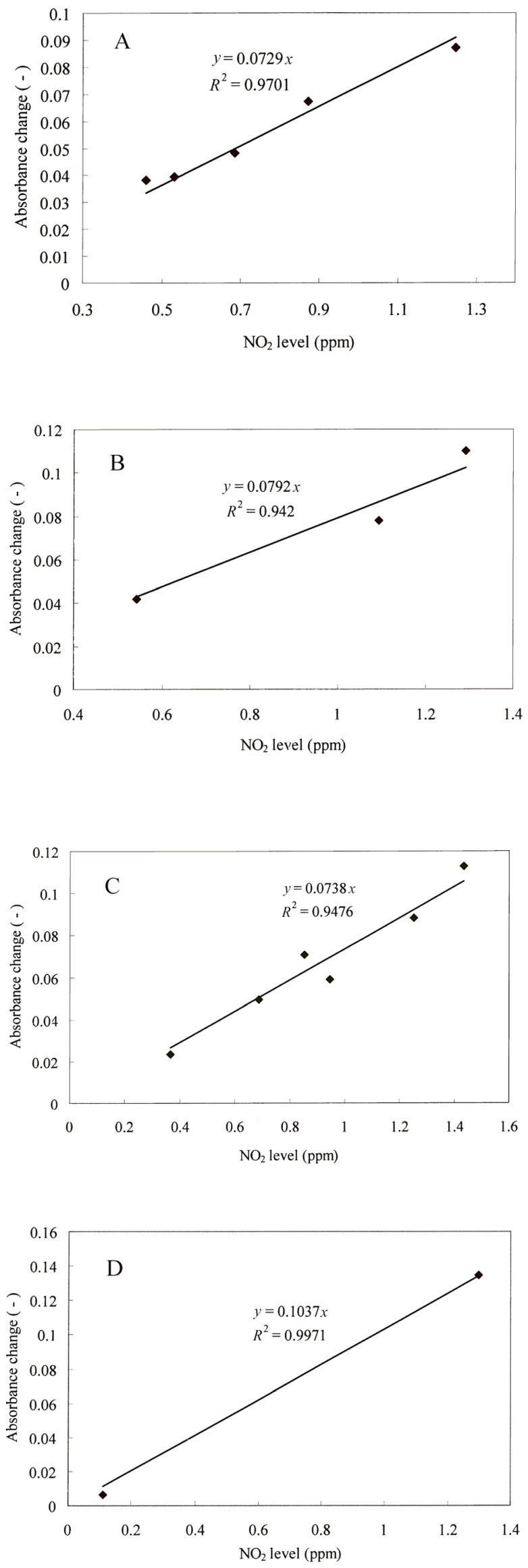

Figure 22. Absorbance change of chemical sensor vs. $\mathrm{NO}_{2}$ level in the chamber at (A) $68{ }^{\circ} \mathrm{C}$ and $20 \%$; (B) $49{ }^{\circ} \mathrm{C}$ and $20 \%$ $\mathrm{RH}$; (C) $49^{\circ} \mathrm{C}$ and $60 \% \mathrm{RH}$; (D) standard $\mathrm{NO}_{2}$ levels 


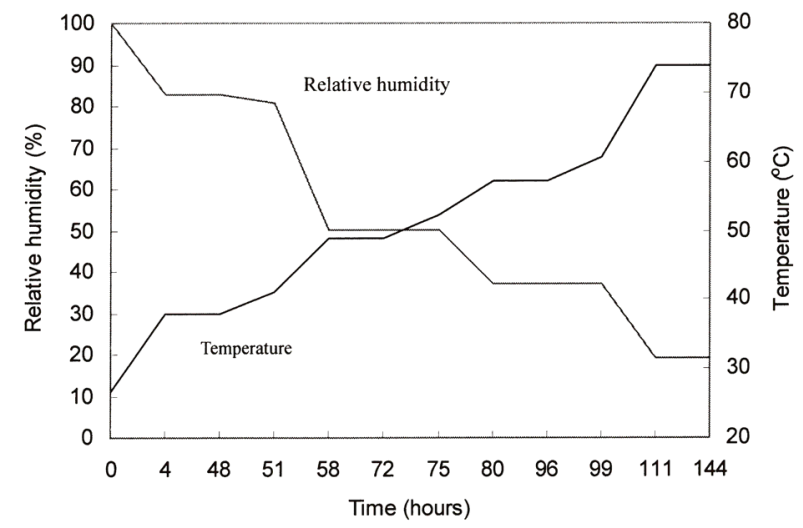

Figure 23. A typical tobacco curing schedule
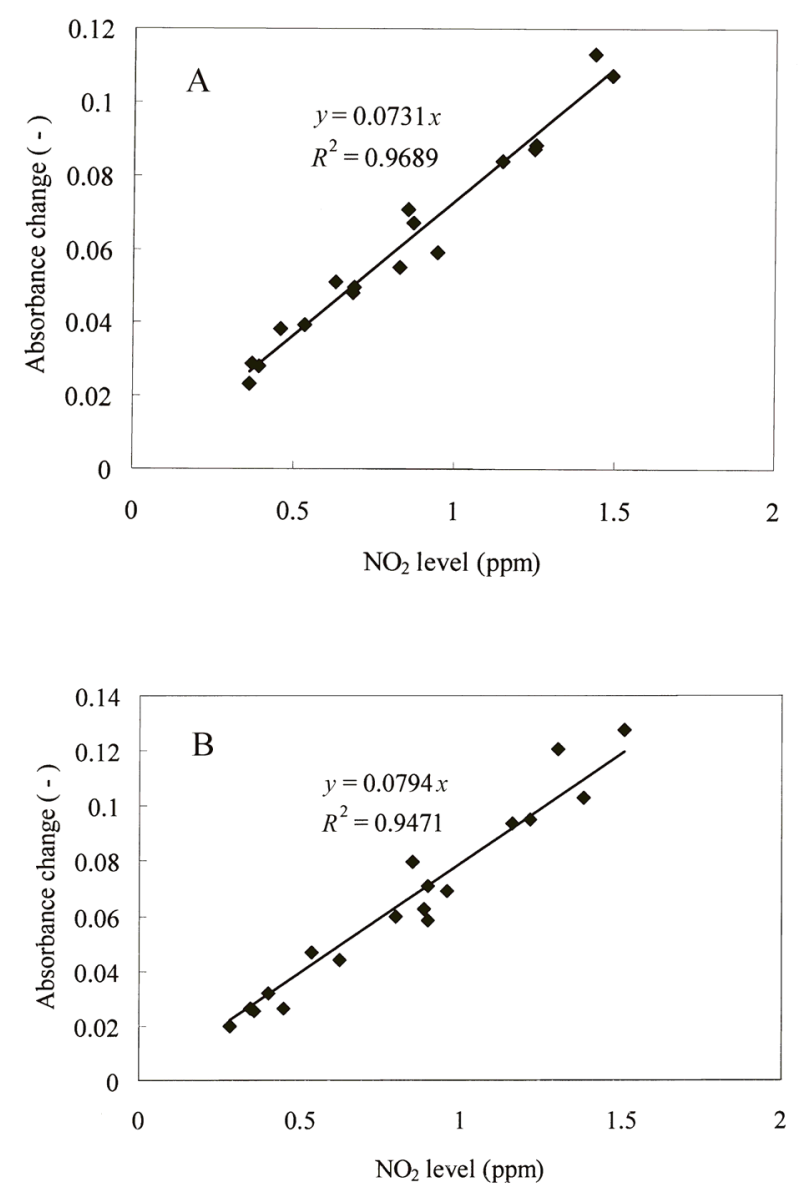

Figure 24. Absorbance changes of sensors measured in the experimental chamber at various temperatures and RHs (A) without a cooler; (B) with a cooler

curing phases. However, as described above, temperature and RH both negatively affected the sensitivity of the sensors. Also, the yellowing phase involves low temperature and high RH, whereas the two drying phases involve higher temperature and lower RH. Thus, it was assumed that each phase of the tobacco-curing process has a similar coefficient in the calibration line. In fact, Figure 24A showed satisfactory linearity among the three phases by obtaining a single calibration line including temperature $\left(35-68^{\circ} \mathrm{C}\right)$ and $\mathrm{RH}$ range (20-80\%) with regard to them. To decrease the temperature and $\mathrm{RH}$ of sample gas, a cooler consisting of a

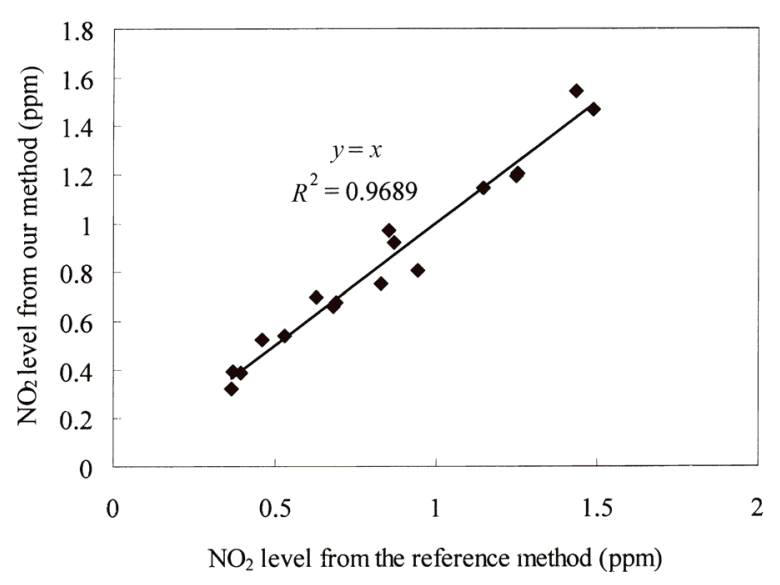

Figure 25. Comparison between $\mathrm{NO}_{2}$ levels measured without a cooler by the reference method and by the instrument described herein

flask and ice was employed for tests. As expected, the coefficient of the calibration line in Figure 24B was slightly greater than the result without the cooler, but the stability of this method was not better. That was because condensed water in the flask and the temperature lowered by ice melting during long-term experiments caused some errors in the measurement. Figure 25 showed good agreement through comparison of $\mathrm{NO}_{2}$ levels between the reference method and our developed instrument without a cooler.

\section{Conclusions}

We have already developed the low-cost opto-electronic system to efficiently measure ppb-level $\mathrm{NO}_{2}$ in environmental air or exhaust gas by colorimetry. Because that color change is formed by reaction between $\mathrm{NO}_{2}$ and a colorimetric reagent ( $o$-tolidine) on filter paper as a sensor, it is very important to know those various characteristics.

First, the optimum lifetime of the sensors preserved in a vacuum package was found to be about 9 days, during which their sensitivities at even low $\mathrm{NO}_{2}$ concentration were wellmaintained. In addition, the relative standard deviation of absorbance changes of the sensors at the lower concentration of $\mathrm{NO}_{2}$ was larger than that of the higher one during storage, because the sensors could be continuously contaminated by ambient $\mathrm{NO}_{2}$. After unpacking the vacuum package of the sensors for field tests, the sensitivities of sensors stored in a vinyl bag again were well maintained for least $6 \mathrm{~h}$.

It was found that temperature and $\mathrm{RH}$ had negative effects on sensor sensitivity. To apply the instrument described herein to the tobacco-curing process, the optimized coefficient of the calibration line for it was determined. Comparison of $\mathrm{NO}_{2}$ levels determined by a reference method and the method described herein indicated good agreement. Also, even though temperature and $\mathrm{RH}$ in each phase of the tobacco-curing process varied widely, the phases had a similar coefficient on their calibration lines.

\section{REFERENCES}

1. Baron, M.G., R. Narayanaswamy, and S.C. Thorpe: Luminescent porphyrin thin films for $\mathrm{NO}_{\mathrm{x}}$ sensing; Sensors and Actuators B11 (1993) 195-199. 
2. Furuki, M., K. Ageishi, S. Kim, I. Ando, and L.S. Pu: Highly sensitive $\mathrm{NO}_{2}$ optical detector with squarylium dye Langmuir-Blodgett film containing J aggregate; Thin Solid Films 180 (1989) 193-198.

3. Nakano, N.: Development of a monitoring tape for nitrogen dioxide in air; Anal. Chim. Acta 321 (1996) 41-45.

4. Yanagisawa, Y. and H. Nishimura: A badge-type personal sampler for measurement of personal exposure to $\mathrm{NO}_{2}$ and $\mathrm{NO}$ in ambient air; Environ. Int. 8 (1982) 235-242.

5. Diamond, P.: Evaluation of a colorimetric personal dosimeter for nitrogen oxide; Environmental Health Laboratory, McClellan AFB CA, Report: EHL-M68M-55, 1968.

6. Leichnitz, K.: Detector tube handbook: Air investigations and technical gas analysis with Dräger tubes; 2nd Edition, 1973.

7. Do, J.S. and W.B. Chang: Amperometric nitrogen dioxide gas sensor: Preparation of PAn/Au/SPE and sensing behaviour; Sensors and Actuators B72 (2001) 101-107.

8. Baldini, F., A. Capobianchi, A. Falai, A.A. Mencaglia, and G. Pennesi: Reversible and selective detection of $\mathrm{NO}_{2}$ by means of optical fibres; Sensors and Actuators B74 (2001) 12-17.

9. Maruo, Y. Y., T. Tanaka, T. Ohyama, and T. Hayashi:: System for detecting environmental ppb-level nitrogen dioxide I; Sensors and Actuators B57 (1999) 135-141.

10. Ohyama, T., Y.Y. Maruo, T. Tanaka, and T. Hayashi: A ppb-level $\mathrm{NO}_{2}$ detection system using coloration reactions in porous glass and its humidity dependence; Sensors and Actuators B64 (2000) 142-146.
11. Heckmann, J.: Colorimetric gas measuring device; United States Patent No. 4,904,449 (1990).

12. Peele, D.M. and J.S. Gentry: Formation of tobaccospecific nitrosamines in flue-cured tobacco; CORESTA Proceedings (1999) Paper No. ST6.

13. Peele, D.M., M.G. Riddick, M.E. Edwards, J.S. Gentry, and T.B. Nestor: Formation of tobaccospecific nitrosamines in flue-cured tobacco; Rec. Adv. Tob. Sci. 27 (2001) 3-12.

14. Doolittle, D.J., J.T. Avalos, B.R. Bombick, K.P. Putnam, D.W. Bombick, T.B. Nestor, and J.S. Gentry: Biological studies on smoke condensates from cigarettes made with low nitrosamine flue-cured tobacco; $54^{\text {th }}$ Tobacco Science Research Conference, Program Booklet and Abstracts, Vol. 54, Paper No. 45, 2000. pp. 44-45; CORESTA Congress, Lisbon, Portugal, CORESTA Information Bulletin, Special Edition (2000) Paper ST23, p. 168.

15. Boyette, M.D. and R.W. Watkins: Guide for bulk curing tobacco in North Carolina; The North Carolina Agricultural Extension Service, Raleigh NC, AG-101 (1991).

\section{Corresponding author:}

I.H. Oh

$K T \& G$ Central Research Institute 302 Shinseong-dong, Yuseong-gu

Daejeon 305-805

South Korea

E-mail: ihoh@ktng.com 